\title{
Influence of Deuterium-Depleted Water on the Isotope D/H Composition of Liver Tissue and Morphological Development of Rats at Different Periods of Ontogenesis
}

\author{
Alexandr Alexandrovich Basov ${ }^{1,2}$, Anna Anatolyevna Elkina ${ }^{2 *}$, Andrei \\ Alexandrovich Samkov ${ }^{2}$, Nikita Nikolaevich Volchenko ${ }^{2}$, \\ Arcadii Victorovich Moiseev ${ }^{3}$, Liliya Viacheslavovna Fedulova ${ }^{4}$, Mikhail \\ Gennadievich Baryshev ${ }^{2}$ and Stepan Sergeevich Dzhimak ${ }^{2,4}$
}

${ }^{1}$ Kuban State Medical University, Krasnodar, Russian Federation, Russia; ${ }^{2}$ Kuban State University, Krasnodar, Russian

Federation, Russia; ${ }^{3}$ Kuban State Agrarian University, Krasnodar, Russian Federation, Russia; ${ }^{4}$ The V.M. Gorbatov

Federal Research Center for Food Systems of Russian Academy of Sciences, Moscow, Russian Federation, Russia

Received 5 May 2018; revised 1 July 2018; accepted 15 July 2018

\begin{abstract}
Background: This study aimed to evaluate the reaction of organism of laboratory animals on deuterium-depleted drinking diet. To assess the cell energy metabolism, the effect of a liquid medium with different deuterium contents on isolated liver mitochondria of random bred rats and Wistar rats was studied. Methods: This experimental study on the effect of deuterium-depleted drinking water (DDW) on 16-week-old male Wistar rats lasted for four weeks. Energy metabolism of mitochondria was examined through the production of hydrogen peroxide using an Amplex ${ }^{\circledast}$ Red Hydrogen Peroxide/Peroxidase Assay Kit. Results: Modification of isotope (deuterium-protium $[\mathrm{D} / \mathrm{H}]$ ) composition of rats' blood and organ tissues with DDW $(-705 \%)$, introduced into rats' diet within four weeks, led to the formation of isotope $\mathrm{D} / \mathrm{H}$ gradient between blood plasma and organ tissues and affected isotope $\mathrm{D} / \mathrm{H}$ exchange reactions on the adaptive processes. The isolated liver mitochondria from the random bred rats consumed DDW presented a maximum increase in $\mathrm{H}_{2} \mathrm{O}_{2}$ production during the incubation in DDW medium. This increased level of $\mathrm{H}_{2} \mathrm{O}_{2}$ production was higher in the isolated liver mitochondria of the rats consuming natural deuterium content drinking water $(-24 \%)$. Conclusion: The obtained results indicate the possibility of nutritional correction of isotope $\mathrm{D} / \mathrm{H}$ metabolism in blood by means of products with modified isotope composition, as well as the prospects of using isotope exchange reactions in case of imbalance in function of the body's defense systems in different generations of animals. DOI: 10.29252/ibj.23.2.129
\end{abstract}

Keywords: Deuterium, Mitochondria, Rats, Tissues

Corresponding Author: Anna Anatolyevna Elkina

Kuban State University, Krasnodar, Russian Federation, Russia; Tel.: (+7-91) 80688381; Fax: (+8-861) 2199519; E-mail: 013194@mail.ru

\section{INTRODUCTION}

$\mathrm{T}$ Thanks to modern development of technologies, it has become possible to obtain water with specified ratio of light and heavy isotopes, in particular, ${ }^{1} \mathrm{H} /{ }^{2} \mathrm{H}$ and ${ }^{16} \mathrm{O} /{ }^{18} \mathrm{O}^{[1]}$. Under natural conditions, such pure water $\left({ }^{1} \mathrm{H}_{2}{ }^{16} \mathrm{O}\right)$ cannot exist; therefore, to obtain it, either a delicate multi-stage purification of natural water is carried out, or it is synthesized from ${ }^{1} \mathrm{H}$ and ${ }^{16} \mathrm{O}^{[1,2]}$. The consumption of deuterium-depleted water (DDW) leads to a change in deuterium-protium $(\mathrm{D} / \mathrm{H})$ ratio in body tissues due to isotope exchange reactions, mainly activated by entropy changes observed in the living system ${ }^{[3]}$.

The reactions of isotope $(\mathrm{D} / \mathrm{H})$ exchange between the liquid consumed and blood plasma occur quickly 
enough $^{[4]}$. This matter would be the reason for carrying out studies on stable isotopes of biogenic elements in biological fluids and tissues. Some examples are the investigation of migration routes of wild animals ${ }^{[5]}$ or finding out where a person is living ${ }^{[6]}$. According to Chesson and co-authors ${ }^{[7]}, \delta^{2} \mathrm{H}$ and $\delta^{18} \mathrm{O}$ indices in local tap water are very clearly correlated with the concentration of such isotopes in the body of a person living in a given area.

A number of studies have pointed out the diverse effects of isotope exchange reactions on the functional activity of biological systems, their native properties and structural organization ${ }^{[8-10]}$. However, most of the biological effects involving changes in isotope composition of biogenic elements in the body are still under investigation, and the primary concern is the effect of lower (compared to natural) concentrations of heavy non-radioactive isotopes on living systems. The latter is often associated with the traditional explanation of kinetic isotope effects, which is based on the idea that increase in their intensity is proportional to the concentration of heavy isotopes. In this case, however, isotope effects are associated with a deliberate decrease in the concentration of heavy nonradioactive isotopes in comparison to their natural concentration $^{[11]}$. According to data found in literature, among works describing changes in the proportion of isotopes of biogenic elements, those devoted to the effect of various deuterium concentrations $(\delta \mathrm{D})$ on the body are most frequently found, which can be explained by more pronounced isotope differences in nuclear masses of ${ }^{1} \mathrm{H}$ and ${ }^{2} \mathrm{H}$ in comparison to corresponding indices of atomic weight ratio of stable isotopes of oxygen, carbon and nitrogen. However, despite the increasing number of studies on the impact of low $\delta \mathrm{D}$ product on living systems, these studies mainly focus on alterations in isotope $\mathrm{D} / \mathrm{H}$ ratio in blood plasma ${ }^{[12-14]}$. These investigations are not often adequate to comparatively study $\delta \mathrm{D}$ in body tissues and fluids during the active consumption of water containing modified isotope composition with reduced deuterium content ${ }^{[15]}$.

In general, the effect of DDW consumption on isotope composition of tissues and morpho-functional indices in multicellular organisms have not been studied extensively; nevertheless, this area is of particular interest since studying the morpho-functional status is one of the most informative ways of tracing individual development of an organism, as well as its health condition, and consumption of DDW affects the adaptive capacity of the organism in different periods of ontogenesis.

It is very important to make right choice of the purpose of research that would allow to estimate properly the diversity of the effect of isotope exchange reactions produced on biological systems, which seems to be essential in such scientific work. In scientific literature, one can find studies of various unicellular and multicellular organisms ${ }^{[16-18]}$ that are often presented in a discrete form, without taking into account the genetic heterogeneity of the studied subjects.

It is known that the general body responsiveness of outbred rats, for example, Wistar rats, is significantly lower due to low genetic heterogeneity than that of random bred animals of the same species ${ }^{[19,20]}$. In this regard, studies of the body's adaptive capabilities under the influence of certain ambient factors (such as isotope $\mathrm{D} / \mathrm{H}$ composition of the surrounding medium) are advisable to be conducted in both outbred and random bred rats. These investigations would make it possible not only to evaluate some specific reactions observed in the process of the isotope gradient change (in Wistar rats) but also to determine the entire range of adaptive responses (in random bred rats) which is important for the identification of accompanying morpho-functional effects associated with changes in the isotope $\mathrm{D} / \mathrm{H}$ composition of the water consumed $^{[21,22]}$.

The aim of the present study was to study the effect of isotope $\mathrm{D} / \mathrm{H}$ exchange reactions on biochemical processes, cell energy metabolism, and the morphofunctional state of outbred and random bred rats in case of DDW consumption.

\section{MATERIALS AND METHODS}

DDW was produced on a plant designed in Kuban State University (Russia) by using electrolytic decomposition method ${ }^{[2]}$, with the initial concentration of deuterium in the water produced to amount of $-705 \%$ (hereinafter indicates deuterium content), which was the lowest possibly attainable deuterium depletion degree for the plant in use. The water was further mineralized to use in animal experiments. Mineralization of the prepared water was performed by the addition of salts to obtain a physiologically highgrade mineral composition identical to that of water with deuterium content of -705 and $-24 \%$. As a result, mineral content of produced DDW was 314-382 mg/l, which included $144-180 \mathrm{mg}$ of hydrocarbons, less than $1 \mathrm{mg}$ of sulfates, $60-76 \mathrm{mg}$ of chlorides, $6 \mathrm{mg}$ of calcium, $3 \mathrm{mg}$ of magnesium, $50-58 \mathrm{mg}$ of sodium, and 50-58 $\mathrm{mg}$ of potassium.

The concentration of deuterium in the produced water was determined by means of a JEOL JNM-ECA $400 \mathrm{MHz}$ pulsed nuclear magnetic resonance 
spectrometer $^{[23]}$. To determine the isotope $\mathrm{D} / \mathrm{H}$ composition, liver samples $(3.0 \pm 0.1 \mathrm{mg}$ each $)$ were preliminarily freeze-dried using a lyophilizer ("LS1000"; Prointech, Russian Federation) ${ }^{[24]}$. To determine the isotope $\mathrm{D} / \mathrm{H}$ composition of the rats' liver tissues and blood plasma, a DELTA ${ }^{\text {plus }}$ mass spectrometer equipped with a peripheral H/Device (Finnigan, Germany) was used for sample preparation of liquid for isotope analysis of hydrogen.

The biochemical studies were carried out by means of an biochemical autoanalyzer Chem Well $2900 \mathrm{~T}$ (USA), using Spinreact reagents (Spain). In the present study, the plasma levels of liver function biochemical markers, including bilirubin, aspartate aminotransferase (AST), and alanine aminotransferase (ALT) (De Ritis Ratio: AST/ALT × 100) were measured.

The animals were managed, fed, attended, manipulated and removed from the experiment in accordance with the International Recommendations (the code of ethics). The use of animals in the experiments was approved by an ethical expertise (the local ethical committee of "The Gorbatov's All-Russian Meat Research Institute" FSBSI (No. 5 of 07.12.2016). The rats were kept in standard vivarium conditions: temperature $20 \pm 3{ }^{\circ} \mathrm{C}$, humidity $48 \pm 2 \%$, day/night lighting mode (from 6.00 a.m. to 6 p.m./from 6 p.m. to 6.00 a.m.), and free access to water and food. The rats were placed in plastic cages (TECNIPLAST type IV S), no more than four rats in each ${ }^{[25]}$. Throughout the experiment, the animals consumed standard complete feed. The safety of the experimental animals in both groups was $100 \%$, and their physical activity was monitored during the entire experiment.

The experiment that was conducted to study the effect of DDW on 16-week-old male Wistar rats (obtained from the FSBIS SCBMT FMBA lasted for four weeks. During the experiment, two groups were defined:

(1) Group $1 \mathrm{~W}$, intact rats (control, $\mathrm{n}=8$ ) that were kept under standard conditions during the entire experiment and consumed drinking water with natural deuterium content (-24\%o) ad libitum.

(2) Group $2 \mathrm{~W}$, rats $(n=16)$ that were kept under standard conditions throughout the experiment and consumed DDW (-705\%) ad libitum.

Another experiment which lasted for four weeks was simultaneously carried out to study the effect of DDW on 20-week-old random bred Albino male rats. During the experiment, group 1A (control group) was arranged similar to group $1 \mathrm{~W}$ and group $2 \mathrm{~A}$ (test group) similar to group $2 \mathrm{~W}$.

On $28^{\text {th }}$ day, animals were sacrificed in a euthanasia chamber (Vet Tech Solutions, UK) by means of carbon dioxide. Weight measurements were carried out regularly before each feeding step on the $1^{\text {st }}, 7^{\text {th }}$, and $14^{\text {th }}$ days of the experiment; on $28^{\text {th }}$ day of the experiment, the rats were also weighed, followed by liver and blood sampling. Based on the obtained data, the integral index of chronic intoxication (IICI) was subsequently calculated according to the following formula; the results were presented in conventional units.

$$
\text { IICI }=\left(\mathrm{m}_{\text {liver }} / \mathrm{m}_{\text {animal }}\right) \times 100
$$

To assess the cell energy metabolism, the effect of a liquid medium with different deuterium contents on isolated liver mitochondria of random bred rats and Wistar rats was studied. One half of the samples in groups $1 \mathrm{~W}, 2 \mathrm{~W}, 1 \mathrm{~A}$, and $2 \mathrm{~A}$ were obtained with double-distilled water $(-24 \%)$ as the solvent, and the other half with DDW (-705\%).

To isolate the mitochondria, all the reagents were prepared in $\mu \mathrm{Q}$ 18.2 $\mathrm{MOhm} / \mathrm{cm}$ water (LaboStar TWF 7, Germany). All the mitochondrial isolation steps were carried out on ice using a previously described method ${ }^{[26]}$ with some modifications as below (steps 14).

Step 1 . The freshly extracted liver $(3.0 \pm 0.2 \mathrm{~g})$ was immediately immersed in a special isolation buffer (30 $\mathrm{ml})-0.25 \mathrm{M}$ sucrose solution ( $\mathrm{pH}$ 7.4) containing 0.001 M EDTA (ethylenediaminetetraacetate). The liver sample was then washed three times with (each time 2.5 minutes) the same buffer.

Step 2. The washed liver sample was ground in a Petri dish on ice with a cooled ceramic knife, removing the connective tissues. The resulting (primary) homogenate was again rinsed three times with the isolation buffer (for 2.5 minutes), replacing the used solution with fresh buffer. Then the tissue was manually ground with a ceramic tool, not allowing the temperature to exceed $3{ }^{\circ} \mathrm{C}$. For this purpose, $30 \mathrm{ml}$ of isolation buffer was added to the homogenate once and then it was gently ground for 40 seconds. Another 30 $\mathrm{ml}$ of isolation buffer was added to the resulting (secondary) homogenate. The resulting homogeneous mixture was aliquated to $1.5-\mathrm{ml}$ Eppendorf tubes.

Precipitation was carried out at $600 \times \mathrm{g}$ for 10 minutes, with cooling to $1-2{ }^{\circ} \mathrm{C}$ in a high-speed laboratory cooled centrifuge RS-6MC (Kyrgyzstan). Due to these manipulations, undisturbed cells, large cell fragments and nuclear fraction were removed. The supernatant was carefully transferred into test tubes and kept on ice. The pellet and supernatant residues from the centrifuge tubes were re-suspended, then transferred to a single homogenization vessel and rehomogenized manually on ice for 20 seconds in $25 \mathrm{ml}$ of isolation medium. After this homogenization step, the samples were repeatedly centrifuged. The resulting 
homogeneous mixture was poured into plastic centrifuge tubes; precipitation was carried out at 600 $\times \mathrm{g}$ for 10 minutes, with cooling to a temperature ranging from 1 to $2{ }^{\circ} \mathrm{C}$. The resulting supernatants were combined in one container with supernatant kept on ice.

Step 3. The next step was the precipitation of the mitochondria. For this purpose, the combined supernatant was centrifuged at $14000 \times \mathrm{g}$ for 10 minutes, and cooled to $1-2{ }^{\circ} \mathrm{C}$ in a centrifuge (Hermle Z 36 K, Germany). The supernatant was removed with a micropipette, and the resulting pellets were resuspended and combined with $1 \mathrm{ml}$ of isolation buffer. Then, $30 \mathrm{ml}$ of the buffer was added in small portions with gentle shaking and centrifuged at $14000 \times \mathrm{g}$ for 10 minutes, with cooling to a temperature ranging from 0 to $2{ }^{\circ} \mathrm{C}$. The supernatant was removed with a micropipette, and the resulting pellets were resuspended in $0.25 \mathrm{M}$ sucrose solution $(1 \mathrm{ml})$ lacking EDTA. Then $30 \mathrm{ml}$ of this solution was added in small portions with gentle shaking and centrifuged at 14000 $\times \mathrm{g}$ for 10 minutes, and cooled to $1-2{ }^{\circ} \mathrm{C}$.

Step 4. The supernatant was carefully removed, and $0.5 \mathrm{ml}$ of $0.25 \mathrm{M}$ sucrose solution was carefully layered onto the mitochondria precipitate. The upper loose precipitation layer (about $1 \mathrm{~mm}$ thick) was washed off by gentle shaking and removing by a micropipette. The procedures described in Step 4 were repeated two more times. The resulting solid pellet was then re-suspended in $0.5 \mathrm{ml}$ of $0.25 \mathrm{M}$ sucrose solution (without EDTA). The resulting suspension of isolated mitochondria was immediately used to perform Step 5.

Step 5. The concentration of mitochondria was determined from the protein content by means of the bichinol technique using a standard Pierce TM BSA Protein Assay Kit (USA) in its microplate version. The plate reader, Thermo Scientific Multiskan FC (USA), was used for the measurement.

The mitochondrial suspensions were divided into two equal parts. One part was reacted with $50 \mu \mathrm{M}$ succinate as a substrate for mitochondrial enzymes, and for the second part, no succinate was introduced, and all the redox processes occurred due to the pool of metabolites accumulated in the cell organelles.

The suspension of isolated mitochondria was incubated at $37{ }^{\circ} \mathrm{C}$ for 15 minutes in a phosphate buffer $(\mathrm{pH} 7.4)$ in the presence of $50 \mu \mathrm{M}$ succinate (sodium salt) or without succinate.

According to the studied groups of rats, the following variants of isolated mitochondria were obtained: Mitochondria 1W and Mitochondria 1A, isolated liver mitochondria of rats consumed water with natural deuterium content, incubated in an aqueous medium with deuterium concentration equal to $-24 \%$ (normal concentration); Mitochondria 1Wsuccinate and Mitochondria 1Asuccinate, isolated liver mitochondria of the rats consumed water with natural deuterium concentration, incubated in the presence of $50 \mu \mathrm{M}$ succinate in an aqueous medium with deuterium concentration equal to $-24 \%$ (normal concentration); Mitochondria 2WA and Mitochondria 2AA, isolated liver mitochondria of the pre-adapted rats (group 2), further (before measuring) incubated in an aqueous medium with $\delta \mathrm{D}=-705 \%$; Mitochondria 2WAsuccinate and Mitochondria 2AAsuccinate, isolated liver mitochondria of the pre-adapted rats (group 2), further (before measuring) incubated in the presence of $50 \mu \mathrm{M}$ succinate in an aqueous medium with $\delta \mathrm{D}=-705 \%$; Mitochondria $2 \mathrm{WB}$ and Mitochondria $2 \mathrm{AB}$, isolated liver mitochondria of the pre-adapted rats (group 2), further (before measuring) incubated in an aqueous medium with $\delta \mathrm{D}=-24 \%$; Mitochondria 2WBsuccinate and Mitochondria 2ABsu, isolated liver mitochondria of the pre-adapted rats (group 2), further (before measuring) incubated in the presence of $50 \mu \mathrm{M}$ succinate in an aqueous medium with $\delta \mathrm{D}=-24 \%$;

The concentration of hydrogen peroxide in the incubation medium was measured using an Amplex ${ }^{\circledR}$ Red Hydrogen Peroxide/Peroxidase Assay Kit (USA). The technique is based on the reaction of Amplex ${ }^{\circledR}$ Red reagent with hydrogen peroxide in the presence of horseradish peroxidase in phosphate buffer medium with dimethylsulfuroxide to form colored resofurin ${ }^{[27]}$. The production of hydrogen peroxide by mitochondrial suspensions was measured after preliminary 30-minute incubation of the sample with Amplex ${ }^{\circledR}$ Red Hydrogen Peroxide/Peroxidase Assay Kit in the dark at $25{ }^{\circ} \mathrm{C}$. Absorption was measured using Thermo Scientific Multiskan FC with $\lambda=560 \mathrm{~nm}$.

To investigate the effect of DDW on the perinatal development of rats a 40-week lasting experiment was set. In this experiment, four groups with eight rats in each were defined: two males and six females (one male and three females in one cage):

(1) Group $\mathrm{A}_{0 \_} \mathrm{W}$, intact Wistar rats (F0) that were kept in standard conditions throughout the experiment and consumed natural water (-24\%o) ad libitum; the animals born from those in group $\mathrm{A}_{0} \mathrm{~W}$ formed the first generation (F1) of rats (group $\mathrm{A}_{1-} \mathrm{W}$ ); (2) Group $\mathrm{B}_{0 \_} \mathrm{W}$, Wistar rats (F0) that consumed DDW (-705\%) from the age of four months, eight weeks before mating and then throughout the entire experiment; the animals born from those in group $\mathrm{B}_{0 \_} \mathrm{W}$ formed the first generation ( $\mathrm{F} 1$ ) of rats (group $\mathrm{B}_{1 \_} \mathrm{W}$ ); (3) Group $\mathrm{C}_{0 \_} \mathrm{A}$, intact random bred rats $(\mathrm{F} 0)$ that were kept in standard conditions and consumed natural drinking water (-24\%o) ad libitum; later on, the animals born 
from those in group $\mathrm{C}_{0 \_} \mathrm{A}$ formed the first generation (F1) of rats (group $\mathrm{C}_{1 \_} \mathrm{A}$ ); (4) Group $\mathrm{D}_{0 \_} \mathrm{A}$, random bred rats (F0) that received DDW $(-705 \%)$ from the age of four months, eight weeks before mating and then throughout the experiment; later on, the animals born from those in group $\mathrm{D}_{0 \_} \mathrm{A}$ formed the first generation (F1) of rats (group $\mathrm{D}_{1 \_} \mathrm{A}$ ).

The animals were kept in standard vivarium conditions: temperature $20 \pm 3{ }^{\circ} \mathrm{C}$, humidity $48 \pm 2 \%$, day/night illumination mode (from 6.00 a.m. to 6.00 p.m./from 6.00 p.m. to 6.00 a.m.), free access to water and food. The rats were placed in plastic cages (TECNIPLAST type IV S) with no more than four rats in each cage. Throughout the experiment, the animals consumed standard concentrated complete feed in accordance with GOST R 50258-92.

In groups $A_{1} W$ and $C_{1} A$, infant rats were also given drinking water ad libitum with natural deuterium concentration (-24\%), and those in groups $\mathrm{B}_{1} \mathrm{~W}$ and $\mathrm{D}_{1 \_} \mathrm{A}$ consumed DDW ad libitum (-705\%) throughout the ontogenesis. The infant rats from all the four groups were weighed during three weeks after their birth (on the $1^{\text {st }}, 7^{\text {th }}, 14^{\text {th }}$, and $21^{\text {th }}$ days) in order to evaluate the effect of isotope exchange $(\mathrm{D} / \mathrm{H})$ reactions on the weight gain.

The reliability of the differences in the mean values (M) found between the groups was statistically evaluated using a nonparametric U-test (MannWhitney), the difference was considered reliable for $p<0.05$.

\section{RESULTS}

Rats in groups $1 \mathrm{~W}$ and $2 \mathrm{~W}$ showed no statistically significant changes in body weight (from day 1 to day 28) and liver weight (Table 1); however, increase in appetite and a $5 \%$ increase in feed intake in group $2 \mathrm{~W}$ were observed; physical activity, micturition, and defecation were within the physiological norm. Biochemical indices in blood plasma (ALT, bilirubin, and De Ritis ratio) did not statistically differ in groups $1 \mathrm{~W}$ and $2 \mathrm{~W}$. AST activity index in the blood plasma of rats in group $2 \mathrm{~W}$ was $9 \%$ lower than the same index in rats in group $1 \mathrm{~W}$.

The content of deuterium in the blood plasma of the rats in group $2 \mathrm{~W}$ became 6.2 times lower than that of group $1 \mathrm{~W}$. The content of deuterium in the liver of $2 \mathrm{~W}$ rats became 1.6 times lower than that of $1 \mathrm{~W}$ rats. The change in body weight did not differ statistically in groups $1 \mathrm{~W}$ and $2 \mathrm{~W}$ throughout the experiment (weight gain equaled $13 \%$ in group $1 \mathrm{~W}$ and $10 \%$ in group $2 \mathrm{~W}$ ).

The rats in groups $1 \mathrm{~A}$ and $2 \mathrm{~A}$ showed no statistically significant differences in body weight on day one, whereas on the $7^{\text {th }}$ day of the experiment, a $6 \%$

Table 1. Biochemical and morphological indices in adult male Wistar and random bred rats consumed DDW

\begin{tabular}{|c|c|c|c|c|}
\hline \multirow{2}{*}{ Parameter } & \multicolumn{2}{|c|}{ Wistar rats } & \multicolumn{2}{|c|}{ Random bred rats } \\
\hline & $\begin{array}{l}\text { Group 1W } \\
\text { (152 ppm) }\end{array}$ & $\begin{array}{c}\text { Group 2W } \\
\text { (46 ppm) }\end{array}$ & $\begin{array}{c}\text { Group 1A } \\
(\delta D=-24 \% o)\end{array}$ & $\begin{array}{c}\text { Group 2A } \\
(\delta D=-705 \%)\end{array}$ \\
\hline $\mathrm{m}(1), \mathrm{g}$ & $320.6 \pm 17.3$ & $324.7 \pm 15.6$ & $201.3 \pm 5.7$ & $198.5 \pm 8.6$ \\
\hline $\mathrm{m}(7), \mathrm{g}$ & $334.9 \pm 13.6$ & $326.1 \pm 29.8$ & $207.2 \pm 8.1$ & $187.1 \pm 9.4^{* * * *}$ \\
\hline $\mathrm{m}(14), \mathrm{g}$ & $355.4 \pm 21.3$ & $349.3 \pm 20.4$ & $226.9 \pm 12.5$ & $208.4 \pm 16.7^{* *}$ \\
\hline $\mathrm{m}(28), \mathrm{g}$ & $362.8 \pm 28.6$ & $358.6 \pm 24.5$ & $247.6 \pm 11.4$ & $228.7 \pm 15.9^{* *}$ \\
\hline Liver weight, grams (28) & $10.02 \pm 0.74$ & $9.67 \pm 1.17$ & $7.08 \pm 0.56$ & $5.73 \pm 0.92^{* * *}$ \\
\hline Integral Index of Chronic Intoxication (liver, 28) & $2.77 \pm 0.24$ & $2.72 \pm 0.35$ & $2.87 \pm 0.32$ & $2.53 \pm 0.51$ \\
\hline Aspartate aminotransferase (AST), u/l (28) & $132.57 \pm 13.39$ & $120.43 \pm 42.56$ & $146.72 \pm 13.26$ & $168.29 \pm 15.78^{* * * *}$ \\
\hline Alanine aminotransferase (ALT), u/l (28) & $39.74 \pm 2.95$ & $37.23 \pm 3.91$ & $42.53 \pm 3.62$ & $35.81 \pm 8.60$ \\
\hline De Ritis Ratio (AST/ALT) in unit fractions (28) & $3.36 \pm 0.47$ & $3.29 \pm 1.28$ & $3.46 \pm 0.23$ & $4.94 \pm 1.19^{* * *}$ \\
\hline Bilirubin, micromole/l & $2.84 \pm 0.53$ & $2.66 \pm 0.71$ & $6.27 \pm 2.76$ & $5.98 \pm 1.37$ \\
\hline Deuterium concentration in blood plasma, \%o (28) & $-59.3 \pm 3.1$ & $-367.2 \pm 17.8^{*}$ & $-61.4 \pm 3.0$ & $-374.7 \pm 25.1^{* * *}$ \\
\hline Deuterium concentration in liver, \%o (28) & $-128.7 \pm 8.0$ & $-210.1 \pm 15.4^{*}$ & $-134.6 \pm 12.4$ & $-207.2 \pm 19.3^{* * *}$ \\
\hline
\end{tabular}

${ }^{*} p<0.01$ compared with group $1 \mathrm{~W},{ }^{* *} p<0.05$ in comparison with group $1 \mathrm{~A},{ }^{* * *} p<0.01$ in comparison with group $1 \mathrm{~A}$. The parentheses indicate the day (from the beginning of the experiment) on which the index was measured. 
decrease in body weight was observed in rats of group 2A (Table 1) compared to the first day of the experiment. On the other hand, rats in group $1 \mathrm{~A}$ showed $3 \%$ weight gain. The difference in the body weight of rats in groups $1 \mathrm{~A}$ and $2 \mathrm{~A}(8 \%)$ was still observed on the $14^{\text {th }}$ and $28^{\text {th }}$ days of the experiment. Throughout the experiment, the physiological indices of the rats in groups $1 \mathrm{~A}$ and $2 \mathrm{~A}$ were within the normal range. The liver weight of rats in group $2 \mathrm{~A}$ on day 28 was $18 \%$ lower than that of rats in group 1A, and AST and De Ritis ratio in rats in group $2 \mathrm{~A}$ were 15 and $43 \%$ higher, respectively. No statistically significant differences in ALT activity and bilirubin concentration were observed in groups $1 \mathrm{~A}$ and $2 \mathrm{~A}$.

During the pathoanatomical examination of $1 \mathrm{~W}, 2 \mathrm{~W}$, $1 \mathrm{~A}$, and $2 \mathrm{~A}$ rats, no inflammatory liver changes were detected. The liver was homogeneous dark-red and elastic with no signs of pathology. The IICI index did not differ statistically in groups $1 \mathrm{~W}$ and $2 \mathrm{~W}$, as well as in groups $1 \mathrm{~A}$ and $2 \mathrm{~A}$, indicating that there was no chronic intoxication in rats when DDW was consumed. The content of deuterium in the blood plasma of rats in group 2A was 6.1 times lower than that of rats in group 1A. Deuterium content in the liver of $2 \mathrm{~A}$ rats was 1.5 times lower than that of $1 \mathrm{~A}$ rats, which indicates that the high ability of integral biological fluids to change their isotope composition depends on the content of deuterium in consumed water. The experiment also showed some differences in the dynamics of the specific production of hydrogen peroxide by the isolated liver mitochondria of random bred rats that had undergone preliminary adaptation. Their mitochondria were further incubated (before measurement) in aqueous media with $\delta \mathrm{D}=-705 \%$ ("mitochondria 2AA") and $\delta \mathrm{D}=-24 \%$ ("mitochondria $2 \mathrm{AB}$ "), in order to study the stability of the preadaptation effect in the case of the changed isotope composition of the liquid medium (Fig. 1A and 1C). However, the isolated liver mitochondria of the rats consumed drinking water of natural deuterium content were incubated in an aqueous medium corresponding to a natural one (-24\%o, "mitochondria $1 \mathrm{~A} ")$, as shown in Figure 1B.
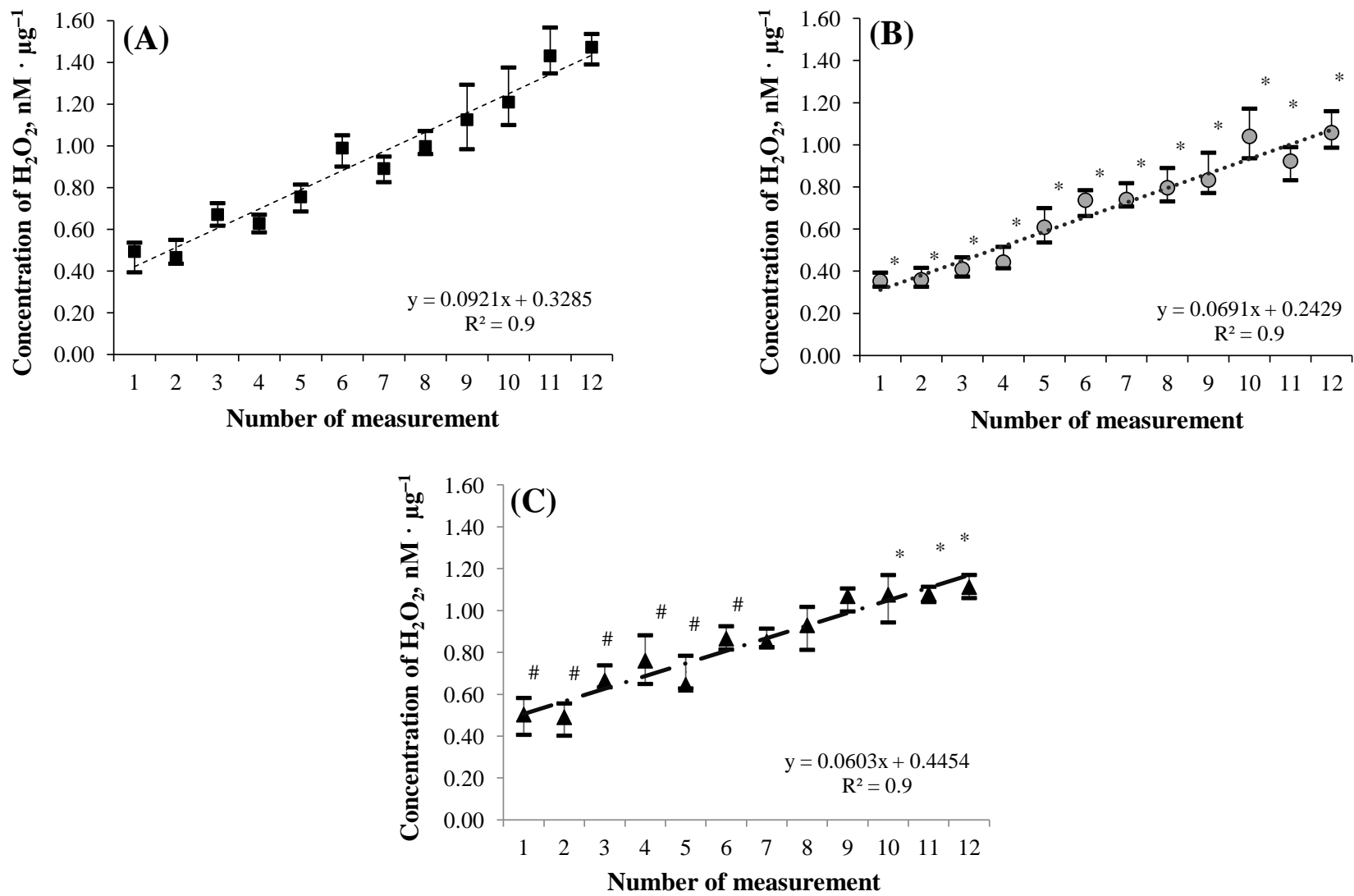

Fig. 1. The dynamics of hydrogen peroxide specific production by isolated mitochondria of rat liver depending on the water consumption and the isotope composition of the water in the mitochondrial incubation medium. Concentration of $\mathrm{H}_{2} \mathrm{O}_{2}$ is presented in nanomoles per microgram of mitochondrial protein $\left(\mathrm{nM} \cdot \mu \mathrm{g}^{-1}\right) * p<0.05$ in comparison to mitochondria $2 \mathrm{AA}(1$ is the number of measurement in 0 minutes from the beginning of the experiment, accordingly 2 - in 10, 3-in 20, 4- in 30, 5- in 40, 6-in $50,7-$ in $60,8-$ in $70,9-$ in $80,10-$ in $90,11-$ in 100 , and $12-$ in 110 minutes); \# $p<0.05$ in comparison to mitochondria $1 \mathrm{~A}$. 
The isolated mitochondria of pre-adapted rats incubated in a medium with reduced deuterium content ("mitochondria 2AA") produced more hydrogen peroxide than isolated "mitochondria $1 \mathrm{~A}^{\text {" throughout }}$ the experiment ( 0 to $110^{\text {th }}$ minutes), with the maximum increase in the hydrogen peroxide produced by "mitochondria $2 \mathrm{AA}^{\text {" by }}$ the $110^{\text {th }}$ minute being $35.3 \%$ ( $p=0.0011$ ) higher than that produced by the isolated "mitochondria 1A" $\left(\mathrm{M} \pm \sigma=1.068 \pm 0.119 \mathrm{nM} \cdot \mu \mathrm{g}^{-1}\right.$ of mitochondrial protein). Upon the addition of $50 \mu \mathrm{M}$ succinate to the suspension of isolated mitochondria of groups $1 \mathrm{~A}$ and $2 \mathrm{~A}$, the latter produced more hydrogen peroxide (Fig. 2). At the same time, the increase in the production of hydrogen peroxide by the $110^{\text {th }}$ minute in the "mitochondria 2AAsu" was $44.1 \%$ higher compared to "mitochondria 2AA" $(\mathrm{M} \pm \sigma=1.445 \pm$ $0.129 \mathrm{nM} \cdot \mu^{-1}$ of mitochondrial protein). The increase in the production of hydrogen peroxide by the $110^{\text {th }}$ minute of the experiment in "mitochondria 1Asu" was $67.4 \%$ higher than that in "mitochondria $1 \mathrm{~A}$ ".

It was also notified that in the presence of $50 \mu \mathrm{M}$ succinate in the suspension of "mitochondria

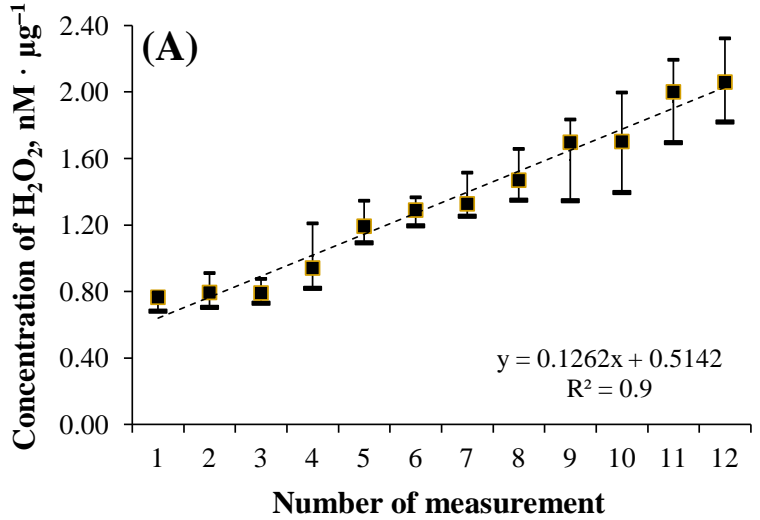

1Asuccinate" and "mitochondria 2AAsuccinate", differences in the production of hydrogen peroxide were observed from the beginning $(0 \mathrm{~min})$ till the $20^{\text {th }}$ minute of the experiment, reaching the maximum differences at the $20^{\text {th }}$ minute $\left(\mathrm{M} \pm \sigma_{\text {«mitochobdria } 1 \text { Asu» }}=\right.$ $0.645 \pm 0.1226 \mathrm{nM} \cdot \mu^{-1}$ of mitochondrial protein, $\mathrm{M} \pm$ $\sigma_{\text {«mitochondria } 2 \mathrm{AAsu}}=0.811 \pm 0.149 \mathrm{nM} \cdot \mu_{\mathrm{g}}^{-1}$ of mitochondrial protein, $p=0.0357$ ), whereas after that, no differences were observed up to the $110^{\text {th }}$ minute ( $p$ $=0.0742$ ).

To check if the detected effect of in vivo preincubation in a medium with reduced deuterium concentration could be preserved, liver mitochondria of rats from group $2 \mathrm{~A}$ were incubated in a medium with a natural deuterium concentration $(-24 \%)$. When the isolated liver mitochondria of pre-adapted rats were placed in the reaction system prepared on the basis of water with natural deuterium concentration $(-24 \%)$, an increased synthesis of hydrogen peroxide in the medium without succinate was observed during the first measurement: it was $36.8 \%(p=0.0063)$ higher than that of "mitochondria $1 \mathrm{~A} "$. Moreover, significant

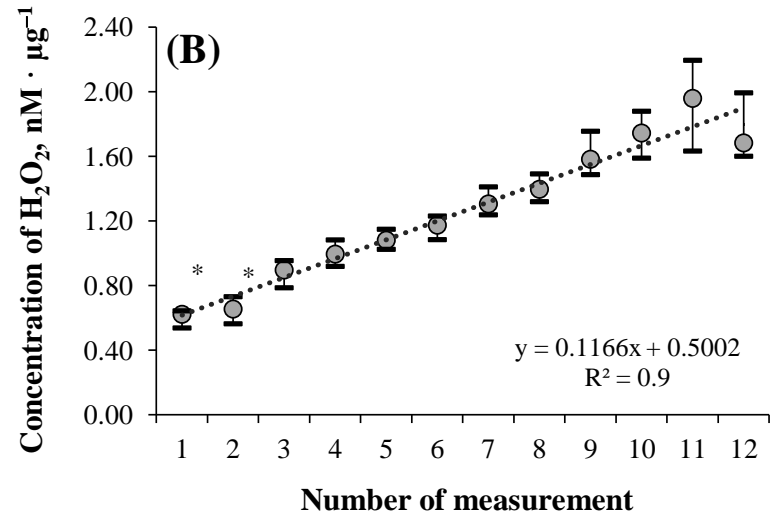

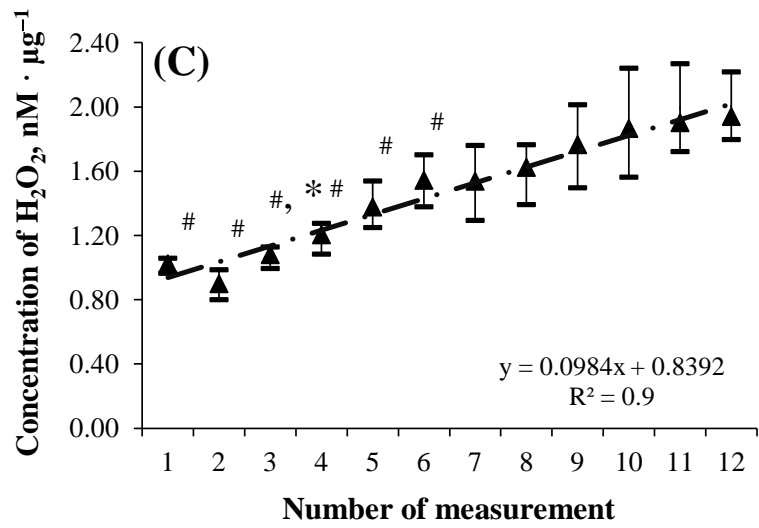

Fig. 2. The dynamics of hydrogen peroxide specific production by isolated mitochondria of rat liver, depending on the water consumption, the isotope composition of the water in the mitochondrial incubation medium and the presence of succinate. The succinate concentration equaled 50 micromoles per liter. ${ }^{*} p<0.05$ compared with mitochondria 2AAsu; \# $p<0.05$ compared with mitochondria 1 Asu ( 1 is the number of measurement in 0 minutes from the beginning of the experiment, accordingly $2-$ in $10,3-$ in $20,4-$ in 30, 5- in 40, 6-in 50,7- in 60, 8- in 70, 9- in 80,10-in 90, 11- in 100, and 12- in 110 minutes). The concentration of $\mathrm{H}_{2} \mathrm{O}_{2}$ is presented in nanomoles per microgram of mitochondrial protein $\left(\mathrm{nM} \cdot \mu \mathrm{g}^{-1}\right)$. 
Table 2. The dynamics of body weight of the 1st generation (F1) random bred rats during the first three weeks of postnatal development.

\begin{tabular}{|c|c|c|}
\hline Parameter & Group $C_{1 \_} A(-24 \% o)$ & Group D $D_{1 \_} A(-705 \%)$ \\
\hline $\begin{array}{l}\text { m (1), g; } \\
\text { group } C_{1 \_} A(n=54) \\
\text { group } D_{1 \_} A(n=37)\end{array}$ & $5.7 \pm 0.8$ & $5.5 \pm 0.3$ \\
\hline $\begin{array}{l}\text { m (7), g; } \\
\text { group } C_{1 \_} A(n=47) \\
\text { group } D_{1 \_} A(n=34)\end{array}$ & $10.1 \pm 0.9$ & $8.4 \pm 1.0 *$ \\
\hline $\begin{array}{l}\text { m (14), g; } \\
\text { group } C_{1 \_} A(n=46) \\
\text { group } D_{1 \_} A(n=34)\end{array}$ & $13.6 \pm 1.7$ & $13.5 \pm 1.2$ \\
\hline $\begin{array}{l}\text { m }(21), g ; \\
\text { group } C_{1 \_} A(n=46) \\
\text { group } D_{1 \_} A(n=34)\end{array}$ & $17.3 \pm 1.6$ & $19.2 \pm 1.5 *$ \\
\hline
\end{tabular}

differences were observed till the $60^{\text {th }}$ minute of the experiment (Fig. 1B and 1C), then the differences were leveled and were not observed any more by the $110^{\text {th }}$ minute $(p=0.3446)$. Similar changes were observed when succinate was added with an ultimate concentration of $50 \mu \mathrm{M}$; the difference during the first measurement was $69.2 \%(p=0.0008)$ and preserved till the $50^{\text {th }}$ minute of the experiment (Fig. $2 \mathrm{~B}$ and $2 \mathrm{C}$ ). From the $60^{\text {th }}$ minute, the differences elevated and were no longer observed after the $110^{\text {th }}$ minute of the experiment $(p=0.0929)$.

The mathematical model, most closely described the results of hydrogen peroxide production under the given measurement conditions in isolated mitochondria of rat liver, is a linear model with the following type of equation: $\mathrm{Y}=\mathrm{kX}+\mathrm{b}$. The coefficient of approximation reliability $\left(\mathrm{R}^{2}\right)$ for the presented curves exceeded 0.93 (Figs. 1 and 2), which confirms the correspondence of the obtained linear model to the initial experimental data. Higher energy metabolism in mitochondria could be manifested by a higher body weight gain in random bred infant rats in F1, which was established during the study of their body weight dynamics in postnatal period (Table 2).

During the first days after birth, a less pronounced body weight gain in the first-generation infant rats in group $\mathrm{D}_{1 \_} \mathrm{A}$ was observed with a $17 \%$ increase, reaching the greatest difference compared to $C_{1} A$ group by the end of the first week. On the first day, the number of newborn rats in $\mathrm{C}_{1 \_} \mathrm{A}$ group was $46 \%$ more than in the group of rats that were given DDW. However, the dispersion index (root mean square deviation) of body weight on day one in group $\mathrm{D}_{1 \_} \mathrm{A}$ was $63 \%$ lower than in group $\mathrm{C}_{1 \_} \mathrm{A}$, which indicates reduction in the difference of body weight during a decrease in the number of rats in the litter under the conditions of DDW consumption. Later, at the end of the $2^{\text {nd }}$ week, the dynamics of body weight gain accelerated in the rats of $\mathrm{D}_{1} \mathrm{~A}$ group, while the absolute values of the morphological parameters reached the control group $\mathrm{C}_{1} \_\mathrm{A}$ on the $14^{\text {th }}$ day $(p>$ 0.05 ) and significantly exceeded the rat body weight of this group by $11 \%$ on the $21^{\text {st }}$ day after birth.

Apparently, the change in the isotopic $\mathrm{D} / \mathrm{H}$ gradient indirectly affected pregnant females, causing the birth of a larger percentage of viable rats with less body mass dispersion, due to more development of a smaller number of embryos in the uterus of random bred rats. Thus, on the $7^{\text {th }}$ day, the percentage of dead F1 rats in group $\mathrm{D}_{1 \_} \mathrm{A}$ was $8 \%, 1.6$ times less than the number of dead rats in group $C_{1}$ A that had consumed drinking water of natural deuterium content, although the absolute number of surviving animals in group $\mathrm{C}_{1 \_} \mathrm{A}$ on the $7^{\text {th }}$ day was $38 \%$ higher than that in group $\mathrm{D}_{1} \mathrm{~A}$. On $14^{\text {th }}$ day, the number of surviving rats in group $\mathrm{D}_{1}$ A did not change in comparison to that of the $7^{\text {th }}$ day, whereas in group $\mathrm{C}_{1 \_} \mathrm{A}$, the number of surviving rats was $98 \%$ on the $7^{\text {th }}$ day.

In the case of Wistar rats, no significant differences was observed in the production of hydrogen peroxide between the groups "mitochondria 1W", "mitochondria 2WA", and "mitochondria 2WB". There were also no statistically significant differences between the indices of hydrogen peroxide production in groups "1Wsuccinate mitochondria", "2WAsuccinate mitochondria", and "2WBsuccinate mitochondria" $(p>0.05)$. No statistically significant difference was observed in the body weight of the Wistar rats of F1 generation (Table 3).

During the first seven days, a greater percentage 
Table 3. The dynamics of body weight gain of the 1st generation (F1) Wistar rats during the first three weeks of postnatal development.

\begin{tabular}{|c|c|c|}
\hline Parameter & Group A1_W (-24\%o) & Group B B_W (-705\%o) \\
\hline $\begin{array}{l}\mathrm{m}(1), \mathrm{g} ; \\
\text { group } \mathrm{A}_{1} \mathrm{~W}(\mathrm{n}=59) \\
\text { group } \mathrm{B}_{1-} \mathrm{W}(\mathrm{n}=71)\end{array}$ & $7.1 \pm 0.8$ & $6.9 \pm 1.0$ \\
\hline $\begin{array}{l}\text { m }(7), \text { g; } \\
\text { group } A_{1-W}(n=53) \\
\text { group } B_{1-} W(n=58)\end{array}$ & $14.4 \pm 1.3$ & $14.7 \pm 1.8$ \\
\hline $\begin{array}{l}\mathrm{m}(14), \mathrm{g} ; \\
\text { group } \mathrm{A}_{1} \mathrm{~W}(\mathrm{n}=53) \\
\text { group } \mathrm{B}_{1-} \mathrm{W}(\mathrm{n}=55)\end{array}$ & $23.8 \pm 2.4$ & $26.3 \pm 3.1$ \\
\hline $\begin{array}{l}\text { m }(21), g ; \\
\text { group } A_{1-W}(n=53) \\
\text { group } B_{1-} W(n=55)\end{array}$ & $46.5 \pm 2.6$ & $47.1 \pm 4.3$ \\
\hline
\end{tabular}

The parentheses indicate the day of the experiment on which body weight was measured.

(79\%) of deaths was recorded among infant rats in the F1 litter of the Wistar rats had been consuming DDW compared to group $\mathrm{A}_{1} \mathrm{~W}$; the percentage of dead rats was $10 \%$. This observation may indicate a stressful effect produced by the changing isotopic $\mathrm{D} / \mathrm{H}$ gradient on pregnant females, causing the birth of a significant number of nonviable rats with no differences in morphometric characteristics observed between these rats and the intact ones. Moreover, on the $14^{\text {th }}$ day, the number of surviving infant rats in $\mathrm{F} 1$ was $77 \%$ in group $\mathrm{B}_{1} \mathrm{~W}$, whereas the number of surviving infant rats in group $\mathrm{A}_{1} \mathrm{~W}$ was $14 \%$ higher, which indicates a less stressful effect produced on the young rats in the case of consumption of water with natural deuterium content by the pregnant females. In this case, the absolute number of surviving rats (53 and 55) on day 14 in groups $A_{1 \_} W$ and $B_{1 \_} W$ was almost equal.

\section{DISCUSSION}

The analysis of fluctuations of the isotope $\mathrm{D} / \mathrm{H}$ composition of lyophilized liver tissues showed that small changes in deuterium concentration in the liver may exhibit the presence of sufficiently selective histohematological barriers, restricting to some extents to the amount of heavy isotopes entering hepatocytes and also probably to the formation of intracellular water from alternative substrates with more stable isotope composition, for example, in tricarboxylic acid cycle $^{[28]}$.

More rapid changes in deuterium concentration in blood plasma compared to fluctuations in its concentration in liver tissues cause a change in the direction and magnitude of isotope $\mathrm{D} / \mathrm{H}$ gradient, which under physiological conditions is characterized by the following relation: $\left(\delta \mathrm{D}_{\text {plasma }} / \delta \mathrm{D}_{\text {tissue }}\right)>1$. However, in group 2A rats, the physiological direction of the gradient changed in opposite direction $\left(\left[\delta \mathrm{D}_{\text {plasma }} / \delta \mathrm{D}_{\text {tissue }}\right]<1\right)$.

Such uneven fluctuations in the isotope $\mathrm{D} / \mathrm{H}$ composition of tissues and biological fluids can be characterized by changes in the functional status of the organism due to the development of general nonspecific adaptive reactions that develop in response to the action of any endogenous or exogenous factor.

The uneven decrease in deuterium concentration in the rats' liver and blood plasma can indicate the formation of isotope gradient due to faster reduction of deuterium content in the blood, and the change in the rats' body weight can characterize the process of adaptation of the organism to changing living conditions. The direct influence of DDW on morphofunctional indices and biochemical processes of the organism, in addition to the phenomenon of preliminary adaptation, can also be associated with the enhancement of isotope exchange $(\mathrm{D} / \mathrm{H})$ in active and allosteric sites of enzymes. It is known that $\mathrm{D} / \mathrm{H}$ isotope exchange reactions are mostly active in compounds consisting of atoms with an unshared electron pair and capable of forming intermediate metabolic complexes with the participation of hydrogen bonds, in which protons $\left(\mathrm{H}^{+}\right)$and deuterons $\left(\mathrm{D}^{+}\right)$simultaneously move from one molecule to another. The relatively selective substitution of deuterium for protium in active sites of enzymes is explained by the fact that the hydrogen exchange between water and various hydrogen-containing 
entities under physiological conditions occurs quite easily only in those $\mathrm{A}-\mathrm{H}$ bonds, where the atom $(\mathrm{A}=$ $\mathrm{O}, \mathrm{S}, \mathrm{N})$ contains a free electron pair, or between compounds in a response complex formed via a hydrogen bond. Under natural conditions, there is no exchange in the hydrocarbon linkage $\mathrm{R}_{3} \mathrm{C}-\mathrm{H}(\mathrm{D})$ because the carbon atom does not have a free electron pair. Such selectivity of isotope exchange shows that even an insignificant isotope gradient can produce a selective effect on metabolically active compounds containing the largest number of active atoms having an unshared electron pair and capable of forming hydrogen bonds. On the other hand, a decrease in deuterium content in the hydration shell is also accompanied by changes in the biological activity of macromolecules, which is due to higher frequency and amplitude of vibrations of atomic groupings consisting only of light isotopes. Such rearrangements of biochemical processes in tissues with high metabolic activity (such as in the liver) can affect the morphofunctional indices of the whole organism, for instance, in rats in group 2A. At the same time, no similar changes in morphological parameters were observed in group $2 \mathrm{~W}$ during the experiment, which may indicate a narrower range of adaptive reactions when the isotope gradient is changed in Wistar rats (group 2W), unlike random bred rats (group 2A) apparently having a wider range of adaptive reactions.

Fluctuations in the isotope composition of tissues can lead to an increase in the activity of nonspecific defense systems, which is explained by the phenomenon of preliminary adaptation potentiating the defense mechanisms in cells under stressful conditions caused by various factors (for example, temperature, hypoxia, etc.). A non-specific defense system can react according to a similar mechanism under the conditions of created $\mathrm{D} / \mathrm{H}$ gradient, which may be due to the response of cellular regulatory systems, taking into consideration that a living matter gravitates toward the constancy of the isotope composition corresponding to that of the natural habitat of a biological object. Adaptive responses can also be realized due to a more active deuterium exchange in transcription factors, as well as in the hydration shell of proteins and nucleic acids, which can change their thermodynamic and consequently, thermokinetic characteristics, thus increasing the adaptive capacity of the organism even in the case of relatively insignificant (from 10 to 30\%) exchange of heavy isotopes in tissues. A slightly expressed and slower $\mathrm{D} / \mathrm{H}$ exchange in organs is possible due to the additional amount of deuterium consumed with nutrients.

In order to study the mechanisms of the influence of $\mathrm{D} / \mathrm{H}$ gradient on energy metabolism in the liver, the dynamics of hydrogen peroxide production by isolated mitochondria of rat liver were studied, depending on whether the rats underwent preadaptation to reduced concentration of deuterium in drinking water $(\delta \mathrm{D}=$ $705 \%$ ) in vivo during four weeks and incubation in vitro in a medium with reduced deuterium content $(\delta \mathrm{D}$ $=-705 \%$ ). The mechanism of the biological effect of the changed ratio of stable isotopes of hydrogen $(\mathrm{D} / \mathrm{H})$ is connected with the fact that a liquid medium with reduced deuterium content is directly interrelated with the tricarboxylic acid cycle. This is due to the fact that the enzymes of the tricarboxylic acid cycle localized in the inner mitochondrial volume provide redistribution of deuterium between cytoplasmic and mitochondrial water pools ${ }^{[29]}$. In this case, decrease of $\delta \mathrm{D}$ in cytoplasmic water contributes to the normalization of the phenotype of cells with unbalanced regulation of metabolism. This scenario leads, for example, to a decrease in cancer cells division rate ${ }^{[30]}$.

The preliminary adaptation of rats to a medium with low deuterium content was a part of the present experiment, since it is known that some proton-active enzymes (such as ATPase-dependent proton $\left({ }^{1} \mathrm{H}^{+}\right)$ pump) show selectivity for stable hydrogen isotopes. In particular, they are inhibited to different extents by deuterium $^{[31]}$.

The production of hydrogen peroxide is associated with oxidation-reduction reactions involving energy exchange in the mitochondria. Therefore, the increased production of hydrogen peroxide by mitochondria adapted to a medium with reduced deuterium content may indicate the ability of such mitochondria to synthesize more ATP or other macroergs, which indicates the presence of conditions for the activation of anabolic processes in the body. It is known that the production of hydrogen peroxide by the mitochondria is associated with the formation of reactive oxygen intermediates formed as a result of electron leakage from some components of the respiratory chain ${ }^{[16]}$, and other processes, including the active cycle of tricarboxylic acids. Therefore, since there is no separation of oxidative phosphorylation, the increased production of hydrogen peroxide can be considered as a positive indicator of the effective work of the mitochondrial energy system.

It is known that the generation of hydrogen peroxide by mitochondria in the presence of succinate is a process that is extremely sensitive to the effectiveness of transmembrane proton transfer agents ${ }^{[32]}$. This study showed that in the presence of succinate at $50 \mu \mathrm{M}$ concentration, the differences observed in the medium with low deuterium content gradually elevated. This reduction in the medium may be related to the significantly greater influence of succinate (as the 
reaction substrate) on the rate of redox reactions of the Krebs cycle compared to the effects caused by the formation of deuterium transmembrane gradient in the mitochondria. Thus, it has been shown that the character of the dependence of hydrogen peroxide production on the initial $\mathrm{D} / \mathrm{H}$ ratio within mitochondria is determined by the presence of succinate- one of the intermediates in the tricarboxylic acid cycle- and other metabolic processes in the mitochondria. Similar effects, for instance, those of water with reduced $\delta \mathrm{D}$, may be ascribed to the fact that its consumption increases the production of macroergic compounds in cells (including adenosine triphosphate) and the energy resources of the whole organism during metabolic adaptation at the cellular level ${ }^{[33]}$, which can have a significant effect on the body due to a decrease in intracellular $\delta \mathrm{D}^{[33,34]}$. This matter provides further increase in the rate of reducing reactions involving the deuterium-free form of the reduced nicotinamide adenine dinucleotide phosphate (NADPH) that is necessary for the synthesis of various signal molecules [35]. At the same time, the reduction of deuterium content in a DNA molecule, according to some authors, contributes to the stabilization of its native structure and reduces the risk of replication and transcription failure due to more functional (energetically favorable) protium hydrogen bonds ${ }^{[36]}$. Therefore, a disturbance in mitochondria functioning due to the effect produced by hypoxia, acidosis, or other pathogenic factors on the cell can reduce the content of the deuterium-free form of the reduced $\mathrm{NADPH}$, hence reducing the transfer of ${ }^{1} \mathrm{H}(\mathrm{H}$-transfer occurring in the transhydrogenase reaction) to NADPH. It is possible that these phenomena may be caused by the changes in the transfer of ${ }^{1} \mathrm{H}$ atoms formed in the mitochondria via beta oxidation of fatty acids characterized by a lower deuterium content ${ }^{[37-39]}$. In addition, ${ }^{2} \mathrm{H}$ atoms, the concentration of which is higher in the water and glucose coming to the cytosol from the extracellular medium ${ }^{[40,41]}$, leads in general to an increase in the intracellular $\mathrm{D} / \mathrm{H}$ ratio. Higher values of this ratio can result in a change in the rate, and more rarely, to a change in the direction of biochemical reactions in the body, creating metabolic prerequisites for reducing adaptation and body weight. Thus, in cells with mitochondria with disrupted transfer of ${ }^{1} \mathrm{H}$ atoms, it is possible to regulate the production of macroergic compounds by decreasing the concentration of deuterium in the water consumed, which can correct the growth of cells, their division, and functional disorders $^{[42]}$.

Based on the obtained data, the following conclusions were drawn: in all mitochondrial samples, linear accumulation of hydrogen peroxide was observed throughout the entire duration of the experiment, i.e. for 110 minutes (with 10-minute periodicity of measurements). Apparently, the reactions of isotope $\mathrm{D} / \mathrm{H}$ exchange in the rats of $\mathrm{F} 1$ generation lead to a less pronounced increase in body weight during the first week after their birth. However, later during the third week, the dynamics of growth in the rats of F1 generation exceeded that of the control group, which reflects a faster increase in the long-term adaptive capacity of the organism in the case of reduced deuterium content throughout the ontogenesis, including the antenatal period. The obtained results allow us to speak about the ability of water with reduced deuterium content to increase the potential of the organism defense system during preparing it for subsequent stressful effects or in case of potential development of alternative pathological processes. In general, the obtained results indicate the possibility of nutritional correction of isotope $\mathrm{D} / \mathrm{H}$ exchange in blood by means of products with a modified isotope composition, as well as the prospects of using isotope $\mathrm{D} / \mathrm{H}$ exchange reactions in case of imbalanced function of the body's defense systems ${ }^{[43]}$. All these results can be related to a significantly lower limit of adaptive reactions realization, compared to random bred rats with greater genetic heterogeneity, which allows the latter to implement their individual adaptive capabilities more effectively when facing adverse environmental triggers. However, similar mechanisms of adaptive reactions under stress conditions are accompanied by a decrease in animals' breeding performance, with the formation of a higher adaptive potential in surviving offspring in the postnatal period of its development, which is characterized by greater individual resistance of these rats to environmental effects. Meanwhile, Wistar rats in group $\mathrm{B}_{1 \_} \mathrm{W}$, due to a lower degree of implementation of adaptive reactions to the changing isotopic $\mathrm{D} / \mathrm{H}$ gradient in the females during the pregnancy period, gave birth to a greater number of rats ( $92 \%$ more compared to group $\left.\mathrm{D}_{1 \_} \mathrm{A}\right)$, which demonstrated less ability to adapt to environmental effects.

In general, the obtained results indicate the possibility of nutritional correction of isotope $\mathrm{D} / \mathrm{H}$ metabolism in the blood by means of products with modified isotope composition, as well as the prospects of using isotope exchange reactions in case of imbalance in the work of the body's defense systems in various generations of animals.

\section{ACKNOWLEDGEMENTS}

This work was financially supported by the State 
Task of the Ministry of Education and Science of the Russian Federation (project no. 6.5882.2017).

\section{CONFLICT OF INTEREST. None declared.}

\section{REFERENCES}

1. Yeh HM. Recovery of deuterium from water isotopes in thermal diffusion columns connected in series. Progress in nuclear energy 2010; 52(5): 516-522.

2. Barishev MG, Dzhimak SS, Frolov VU, Bolotin SN, Dolgov MA. Methods for obtaining water with low content of deuterium. International Journal of engineering research and applications 2013; 3(1): 523526.

3. Storm-Suke A, Wassenaar LI, Nol E, Norris DR. The influence of metabolic rate on the contribution of stablehydrogen and oxygen isotopes in drinking water to quail blood plasma and feathers. Functional ecology 2012; 26(5): 1111-1119.

4. Wolf N, Bowen GJ, Martinez del Rio C. The influence of drinking water on the $\delta \mathrm{D}$ and $\delta^{18} \mathrm{O}$ values of house sparrow plasma, blood and feathers. The journal of experimental biology 2011; 214: 98-103.

5. Hobson KA, Atwell L, Wassenaar LI. Influence of drinking water and diet on the stable-hydrogen isotope ratios of animal tissues. Proceedings of the national academy of sciences of the USA 1999; 96(14): 80038006.

6. Lehn C, Lihl C, Roßmann A. Change of geographical location from Germany (Bavaria) to USA (Arizona) and its effect on $\mathrm{H}-\mathrm{C}-\mathrm{N}-\mathrm{S}$ stable isotopes in human hair. Isotopes in environmental and health studies 2015; 51(1): 68-79.

7. Chesson LA, Valenzuela LO, O'Grady SP, Cerling TE, Ehleringer JR. Links between purchase location and stable isotope ratios of bottled water, soda, and beer in the United States. Journal of agricultural and food chemistry 2010; 58(12): 7311-7316.

8. Avila DS, Somlyai G, Somlyai I, Aschner M. Antiaging effects of deuterium depletion on Mn-induced toxicity in a C. elegans model. Toxicology letters 2012; 211(3): 319-324.

9. Xie X, Zubarev RA. Isotopic resonance hypothesis: experimental verification by Escherichia coli growth measurements. Scientific reports 2015; 5: 9215.

10. Cong F, Zhang Y, Sheng H, Ao Z, Zhang S, Wang J. Deuterium-depleted water inhibits human lung carcinoma cell growth by apoptosis. Experimental therapeutical medicine 2010; 1(2): 277-283.

11. Dzhimak SS, Basov AA, Baryshev MG. Content of deuterium in biological fluids and organs: Influence of deuterium depleted water on $\mathrm{D} / \mathrm{H}$ gradient and the process of adaptation. Doklady biochemistry and biophysics 2015; 465(1): 370-373.

12. Luo A-L, Zheng Y-L, Cong F-S. Research progress of biological effects of deuterium-depleted water. Journal of Shanghai Jiaotong University (Medical Science).
2018; 38(4): 467-471.

13. Dzhimak SS, Basov AA, Elkina AA, Fedulova LV, Kotenkova EA, Vasilevskaya ER, Lyasota OM, Baryshev MG. Influence of deuterium-depleted water on hepatorenal toxicity. Jundishapur journal of natural pharmaceutical products 2018; 13(2): e69557. DOI: 10.5812/jjnpp.69557.

14. Wolf N, Bowen GJ, del Rio CM. The influence of drinking water on the deltaD and $\operatorname{delta}_{18} \mathrm{O}$ values of house sparrow plasma, blood and feathers. The journal of experimental biology 2011; 214(Pt1): 98-103.

15. O'Grady SP, Wende AR, Remien CH, Valenzuela LO, Enright LE, Chesson LA, Dale Abel E, Cerling TE, Ehleringer JR. Aberrant water homeostasis detected by stable isotope analysis. PLoS one 2010; 5(7): e11699.

16. Murphy MP. How mitochondria produce reactive oxygen species. Biochemical journal 2009; 417(1): 113.

17. Samkov AA, Dzhimak SS, Barishev MG, Volchenko NN, Khudokormov AA, Samkova SM, Karaseva EV. Effect of water isotope composition on Rhodococcus erythropolis biomass production. Biophysics 2015; 60(1): 136-142.

18. Strekalova T, Evans M, Chernopiatko A, Couch Y, Costa-Nunes J, Cespuglio R, Chesson L, Vignisse J, Steinbusch HW, Anthony DC, Pomytkin I, Lesch KP. Deuterium content of water increases depression susceptibility: The potential role of a serotonin-related mechanism. Behavioral brain research 2015; 15; 237 244.

19. Cools AR, Rots NY, Ellenbroek B, de Kloet ER. Bimodal shape of individual variation in behavior of Wistar rats: the overall outcome of a fundamentally different make-up and reactivity of the brain, the endocrinological and the immunological system. Neuropsychobiology 1993; 28(1-2): 100-105.

20. Nakanishi S, Serikawa T, Kuramoto T. Slc:Wistar outbred rats show close genetic similarity with F344 inbred rats. Experimental animals 2015; 64(1): 25-29.

21. Flagel SB, Robinson TE, Clark JJ, Flagel SB, Robinson TE, Clark JJ, Clinton SM, Watson SJ, Seeman P, Phillips PE, Akil H. An animal model of genetic vulnerability to behavioral disinhibition and responsiveness to reward-related cues: Implications for addiction. Neuropsychopharmacology 2010; 35(2): 388400.

22. Kavelaars A, Heijnen CJ, Tennekes R, Kavelaars A, Heijnen CJ, Tennekes R, Bruggink JE, Koolhaas JM. Individual behavioral characteristics of wild-type rats predict susceptibility to experimental autoimmune encephalomyelitis. Brain behavior and immunity journal 1999; 13(4): 279-286.

23. Dzhimak SS, Basov AA, Kopytov GF, Kashaev DV, Sokolov ME, Artsybasheva OM, Sharapov KS, Baryshev MG. Application of NMR spectroscopy to the determination of low concentrations of nonradioactive isotopes in liquid media. Russian physics journal 2015; 58(7): 923-929.

24. Gubareva EA, Sjöqvist S, Gilevich IV, Sotnichenko AS1, Kuevda EV1, Lim ML, Feliu N, Lemon G, 
Danilenko KA, Nakokhov RZ, Gumenyuk IS, Grigoriev TE, Krasheninnikov SV, Pokhotko AG, Basov AA, Dzhimak SS, Gustafsson Y, Bautista G, Beltrán Rodríguez A, Pokrovsky VM, Jungebluth P, Chvalun SN, Holterman MJ, Taylor DA, Macchiarini P. Orthotopic transplantation of a tissue engineered diaphragm in rats. Biomaterials 2016; 77: 320-335.

25. Guide for the Care and Use of Laboratory Animals: Eighth Edition. Washington: The National Academies Press. 2011; p. 248. Retrieved from: https://grants.nih.gov/grants/olaw/Guide-for-the-careand-Use-of-Laboratory-Animals.pdf

26. Johnson D, Lardy $\mathrm{H}$. Isolation of liver or kidney mitochondria. Methods in enzymology 1967; 10: 94-96.

27. Amplex® Red Hydrogen Peroxide/Peroxidase Assay Kit. [cited 12 February 2017] Author's manuscript available at: https://tools.thermofisher.com/content/sfs/ manuals/mp22188.pdf

28. Kreuzer-Martin HW, Ehleringer JR, Hegg EL. Oxygen isotopes indicate most intracellular water in log-phase Escherichia coli is derived from metabolism. Proceedings of the national academy of sciences of the United States of America 2005; 102(48): 17337-17341.

29. Boros LG, D'Agostino DP, Katz HE, Roth JP, Meuillet EJ, Somlyai G. Submolecular regulation of cell transformation by deuterium depleting water exchange reactions in the tricarboxylic acid substrate cycle. Medical hypotheses 2016; 87: 69-74.

30. Wang H, Zhu B, He Z, Wang H, Zhu B, He Z, Fu H, Dai Z, Huang G, Li B, Qin D, Zhang X, Tian L, Fang W, Yang H. Deuterium-depleted water (DDW) inhibits the proliferation and migration of nasopharyngeal carcinoma cells in vitro. Biomedicine and pharmacotherapy 2013; 67(6): 489-496.

31. Kotyk A, Dvoráková M, Koryta J. Deuterons cannot replace protons in active transport processes in yeast. Federation of European biochemical societies letters 1990; 264(2): 203-235.

32. Pomytkin IA. $\mathrm{H}_{2} \mathrm{O}_{2}$ signalling pathway: A possible bridge between insulin receptor and mitochondria. Current neuropharmacology 2012; 10(4): 311-20.

33. Somlyai G. The Biological Effect of Deuterium Depletion. Budapest: AuthorHouse; 2002.

34. Tannahill GM, Curtis AM, Adamik J, PalssonMcDermott EM, McGettrick AF, Goel G, Frezza C, Bernard NJ, Kelly B, Foley NH, Zheng L, Gardet A, Tong Z, Jany SS, Corr SC, Haneklaus M, Caffrey BE,
Pierce K, Walmsley S, Beasley FC, Cummins E, Nizet V, Whyte M, Taylor CT, Lin H, Masters SL, Gottlieb E, Kelly VP, Clish C, Auron PE, Xavier RJ, O'Neill LA. Succinate is an inflammatory signal that induces IL- $1 \beta$ through HIF-1 $\alpha$. Nature 2013; 496(7444): 238-242.

35. Tedeschi PM, Markert EK, Gounder M, Lin H, Dvorzhinski D, Dolfi SC, Chan LL, Qiu J, DiPaola RS, Hirshfield KM, Boros LG, Bertino JR, Oltvai ZN, Vazquez A. Contribution of serine, folate and glycine metabolism to the ATP, NADPH and purine requirements of cancer cells. Cell death and disease 2013; 4: e877.

36. Zubarev RA, Artemenko KA, Zubarev AR, Mayrhofer C, Yang H, Eva Fung YM. Early life relict feature in peptide mass distribution. Central European journal of biology 2010; 5(2): 190-196.

37. Billault I, Guiet S, Mabon F, Robins R. Natural deuterium distribution in long-chain fatty acids is non statistical: a site-specific study by quantitative ${ }^{2} \mathrm{H}$ NMR spectroscopy. Chembiochem 2001; 2(6): 425-431.

38. Poff AM, Ari C, Seyfried TN, D'Agostino DP. The ketogenic diet and hyperbaric oxygen therapy prolong survival in mice with systemic metastatic cancer. PLoS one $2013 ; \mathbf{8}(6)$ : e65522.

39. Soto DX, Hobson KA, Wassenaar LI. The influence of metabolic effects on stable hydrogen isotopes in tissues of aquatic organisms. Isotopes in environmental and health studies 2013; 49(3): 305-311.

40. Boros LG, Lee PW, Brandes JL, Cascante M, Muscarella P, Schirmer WJ, Melvin WS, Ellison EC. Nonoxidative pentose phosphate pathways and their direct role in ribose synthesis in tumors: Is cancer a disease of cellular glucose metabolism? Medical hypotheses 1998; 50(1): 55-59.

41. Boros LG, Lee WN, Cascante M. Imatinib and chronicphase leukemias. The new England journal of medicine 2002; 347(1): 67-68.

42. Somlyai G. Compositions comprising water with deuterium for the prevention or treatment of allergic diseases and a process for the preparation thereof. Retrieved from: http://www.google.com/patents/ US20120058197.

43. Rehakova R, Klimentova J, Cebova M, Barta A, Matuskova Z, Labas P, Pechanova O. Effect of deuterium-depleted water on selected cardiometabolic parameters in fructose-treated rats. Physiological research 2016; 65(3): S401-S407. 